\title{
Perfil das cooperativas agropecuárias no Noroeste de Minas Gerais
}

Submissão: 24/02/2021

Aceite: $29 / 08 / 2021$

Elias Rodrigues de Oliveira Filho ${ }^{1}$

João Soares Neto ${ }^{2}$

\begin{abstract}
Resumo
No Brasil a expansão das cooperativas tem concepção econômica, pois expressa o esforço de reduzir custos e ampliar as possibilidades no mercado altamente competitivo. Em Minas Gerais, especificamente nos municípios do Noroeste de Minas é significativa à organização coletiva através de cooperativas no ramo agropecuário, seja de grandes, médios e pequenos produtores, reflexo da base econômica centrada na produção de grãos, leite e derivados. Neste contexto, este artigo tem por objetivo apresentar o perfil de algumas cooperativas agropecuárias do Noroeste de Minas. Para tanto, fez-se pesquisa bibliográfica e de dados. Os resultados apontam que as cooperativas exercem importante participação direta e indireta na conjuntura social e econômica dos munícipios, geram emprego, promovem melhorias socioambientais, revitalizam áreas degradadas, enfim, exercem papel social com princípios bem definidos.
\end{abstract}

Palavras-chave: Cooperativas. Noroeste de Minas. Minas Gerais. Desenvolvimento regional.

\section{Dynamics of agricultural cooperatives in Northwestern Minas Gerais}

\begin{abstract}
In Brazil, the expansion of cooperatives has an economic conception, as it expresses the effort to reduce costs and expand possibilities in a highly competitive marketplace. In Minas Gerais, specifically in the municipalities of Northwestern Minas Gerais, the collective organization through cooperatives in the agricultural sector, whether large, medium or small producers, is significant, reflecting the economic base centered on the production of grain, milk and milk products. In this context, this article aims to present the profile of some agricultural cooperatives in Northwestern Minas. For this purpose, a bibliographic and data research was carried out. The results indicate that the cooperatives have an important direct and indirect participation in the social and economic conjuncture of the municipalities, create jobs, promote socio-environmental improvements, revitalize degraded areas; in short, thei exercise a social role with well-defined principles.
\end{abstract}

Keywords: Cooperatives. Northwestern Minas. Minas Gerais. Regional development.

\section{Introdução}

O cooperativismo prima pela autonomia e pelos interesses dos cooperados, portanto busca atender as necessidades da coletividade e promover desenvolvimento socioeconômico. Para tanto, o princípio democrático deve permear a gestão das cooperativas, os membros devem participar de forma ativa das assembleias, reuniões e atuar no processo de decisão. No Brasil, o surgimento e fortalecimento das cooperativas, entre outros motivos, se devem à necessidade de maior competividade e, também, às incertezas da economia interna e externa.

\footnotetext{
${ }^{1}$ Doutorado em Desenvolvimento Regional (UNISC). Professor do Instituto Federal de Educação Ciência e Tecnologia do Norte de Minas Gerais (IFNMG). https://orcid.org/0000-0001-9578-7114 Email:eliasrof@hotmail.com

${ }^{2}$ Mestrado em Zootecnia (UFRRJ). Professor do Instituto Federal de Educação Ciência e Tecnologia do Norte de Minas Gerais (IFNMG). Email: eliasrof@hotmail.com
} 
Conforme a Organização das Cooperativas Brasileiras (OCB, 2019), as cooperativas têm dinamizado vários ramos da economia interna e alavancado as exportações, sendo que em 2018, o cooperativismo foi responsável por $100 \%$ das exportações de 36 municípios brasileiros. Os Estados de São Paulo e Minas Gerais se destacam em número de cooperativas e cooperados. Em

Minas Gerais torna-se crescente a expansão de cooperativas tanto no espaço urbano como no rural, uma vez que a diversidade natural e construída ocasiona muitas realidades. Neste contexto, têm-se os municípios da Mesorregião Noroeste de Minas que contam com rede de cooperativas de grandes, médios e pequenos agropecuaristas. A referida Mesorregião apresenta reduzida densidade demográfica, contudo significativa extensão territorial e produção agropecuária utilizando modernas tecnologias na produção. No entanto, para que se possa avaliar a participação dessas cooperativas no desenvolvimento da região é necessário, preliminarmente, identificar o perfil dessas cooperativas para que, posteriormente, elas possam ser estudadas com maior profundidade e detalhamento quantitativo.

Diante do exposto, este artigo tem como objetivo apresentar, de forma mais qualitativa, o perfil de algumas cooperativas agropecuárias do Noroeste de Minas. A abordagem metodológica consistiu em revisão bibliográfica e levantamento de dados. Os dados da população, as estimativas, a extensão territorial e o ano de instalação dos municípios foram extraídos do Instituto Brasileiro de Geografia e Estatística (IBGE, 2010, 2020). Analisou-se a participação da agropecuária no Produto Interno Bruto dos municípios, disponibilizados pela Fundação João Pinheiro (FJP) e a Diretoria de Estatística e Informações (DIREI, 2020); e por fim, os dados das cooperativas do Brasil e de Minas Gerais foram garimpados do levantamento da OCB (2019).

A partir dos resultados obtidos, pode-se inferir que na Mesorregião Noroeste de Minas as cooperativas do ramo agropecuário têm importância econômica, ambiental e social, dinamizam a economia regional, algumas ultrapassam os limites da referida Mesorregião e do Estado de Minas Gerais e assim promovem melhorias também em outros municípios. As cooperativas do Noroeste de Minas apresentam princípios do cooperativismo que primam pela valorização de cada cooperado, justiça social, liberdade, trabalho coletivo, dentre outros.

\section{Considerações sobre o cooperativismo no Brasil}

O cooperativismo em qualquer sociedade surge como estratégia de determinado grupo de pessoas para atingir um ou mais objetivos que almejam, sendo, pois, uma alternativa que 
valoriza a coletividade. Para Frantz (2012), a própria etimologia do termo cooperativismo deriva do latim "cum", que significa "com, em companhia de, juntamente com" e pelo verbo "operari", que significa "trabalhar", portanto expressa a ideia de trabalhar junto.

A OCB (2019, p.120), define cooperativa e cooperado:

Cooperativa: são sociedades de pessoas, com forma e natureza jurídica próprias, não sujeitas a falência, constituídas para atender seus cooperados, representando-os em operações comerciais, fortalecendo seu poder de negociação e espaço no mercado. Cooperado: São as pessoas físicas ou jurídicas que contribuem para a formação do capital social da cooperativa, e que, ao aderir aos propósitos sociais e preencher as condições estabelecidas no estatuto, tornam-se também beneficiários dos serviços prestados pela cooperativa.

O processo de formação de uma cooperativa pode ser fácil e rápido, porém o fortalecimento e expansão dependem diretamente da corresponsabilidade dos cooperados. 0 movimento cooperativo envolve diversos fundamentos, entre eles, pode-se citar: humanismo com valorização do cooperado; solidariedade; justiça social; liberdade; autodeterminação do ser, inclusive para a cooperação; democracia no processo de decisão pelo bem coletivo; participação ativa, pois todo cooperado é corresponsável em acompanhar a gestão da cooperativa (FRANTZ, 2012).

Nessa perspectiva de acordo com OCB (2019, p.121), os princípios do cooperativismo que devem nortear as cooperativas são "[...] adesão voluntária, gestão democrática, participação econômica dos membros, autonomia e independência, educação, formação e informação, intercooperação e interesse pela sociedade". No Brasil as cooperativas atuam no território nacional e ou no mercado de exportação, conforme levantamento da OCB (2019), a Região Sudeste apresenta o maior número de cooperativas com destaque para os Estados de São Paulo e Minas Gerais (Tabela 1).

Com base nos dados, pode-se identificar que o número de cooperativas em uma Unidade da Federação não significa necessariamente maior número de cooperados, exceção do Estado de São Paulo que apresenta maior volume de cooperativas e cooperados. A Região Sudeste apresenta mais cooperativas, seguida das Regiões Nordeste, Norte, Sul e Centro-Oeste, entretanto, o número de cooperados é maior na Região Sul, na sequência têm-se as Regiões Sudeste, Centro-Oeste, Nordeste e por último a Região Norte.

Os dados dimensionam parcialmente o cenário das cooperativas no Brasil, indicam que muitas pessoas já entenderam que ingressar em uma cooperativa pode auxiliar no processo de organização, produção, comercialização de produtos e ou serviços. As cooperativas podem 
possibilitar melhorias na vida dos cooperados e de outras pessoas, pois criam arranjos produtivos, fortalecem a economia local e regional, geram emprego e renda, logo são responsáveis pelo desenvolvimento socioeconômico.

Tabela 1 - Cooperativas e cooperados no Brasil, em 2018

\begin{tabular}{llrr}
\hline Regiões & Unidades da Federação & № de cooperativas & № de cooperados \\
\hline \multirow{3}{*}{ Sudeste } & São Paulo & 1.025 & 3.093 .354 \\
& Minas Gerais & 771 & 1.738 .917 \\
& Rio de Janeiro & 493 & 180.980 \\
& Espírito Santo & 149 & 444.147 \\
\cline { 2 - 4 } Nordeste & Pernambuco & 280 & 155.177 \\
& Bahia & 205 & 163.505 \\
& Ceará & 169 & 75.168 \\
& Paraíba & 163 & 58.972 \\
& Rio Grande do Norte & 158 & 68.329 \\
& Maranhão & 158 & 28.770 \\
& Piauí & 87 & 9.200 \\
& Sergipe & 79 & 14.336 \\
& Alagoas & 65 & 6.691 \\
\cline { 2 - 4 } Norte & Pará & 541 & 95.867 \\
& Amapá & 165 & 9.339 \\
& Acre & 145 & 10.444 \\
& Roraima & 129 & 4.869 \\
& Amazônia & 128 & 10.320 \\
& Rondônia & 112 & 132.018 \\
Sul & Tocantins & 31 & 28.006 \\
\cline { 2 - 4 } & Rio Grande do Sul & 437 & 2.848 .481 \\
& Santa Catarina & 258 & 2.460 .456 \\
& Paraná & 215 & 1.768 .253 \\
\cline { 2 - 4 } Total & Brasília - Distrito Federal & 367 & 229.870 \\
& Goiás & 219 & 229.477 \\
& Mato Grosso & 168 & 492.729 \\
& Mato Grosso do Sul & 111 & 261.157 \\
\hline & & 6.828 & 14.618 .832 \\
\hline
\end{tabular}

Fonte: OCD (2019). Elaborado pelos autores, 2021.

O cooperativismo brasileiro é diversificado e abrange sete ramos: agropecuário; consumo; crédito; infraestrutura; saúde; trabalho e produção de bens e serviços; e, transporte. Em março de 2019, a OCB aprovou a reorganização dos 13 ramos, existentes até então, em apenas 7 ramos. Do total de 6.828 cooperativas, de 2018, o ramo com maior número de cooperativas era o agropecuário com 1.613. As "Cooperativas de produção agropecuária destinam-se, essencialmente, a prover, por meio da mutualidade, o fomento relacionado às atividades agropecuária, extrativista, agroindustrial, aquícola ou pesqueira” (OCB, 2019, p. 30). 
As cooperativas agropecuárias têm origem no início do século XX e desde 1970 sobressaem no território nacional, especialmente com a modernização do campo. Em Minas Gerais das 771 cooperativas, 193 são do ramo agropecuário (Tabela 2), entre elas estão as cooperativas da Mesorregião Noroeste de Minas, área desta pesquisa.

Tabela 2 - Cooperativas de Minas Gerais, em 2018 (13 ramos)*

\begin{tabular}{lrrr}
\hline Ramos (13) & $\begin{array}{c}\text { № de } \\
\text { cooperativas }\end{array}$ & $\begin{array}{c}\text { № de } \\
\text { cooperados }\end{array}$ & $\begin{array}{c}\text { № de empregados } \\
\text { direto }\end{array}$ \\
\hline Infraestrutura & 1 & 980 & - \\
Mineral & 3 & 309 & 83 \\
Produção & 7 & 59 & 4 \\
Habitacional & 10 & 2.644 & 24 \\
Educacional & 25 & 4.023 & 4.023 \\
Consumo & 29 & 137.284 & 1.102 \\
Trabalho & 39 & 2.570 & 24 \\
Saúde & 124 & 38.689 & 13.027 \\
Transporte & 156 & 16.708 & 1.645 \\
Crédito & 184 & 1.365 .927 & 11.439 \\
Agropecuário & 193 & 169.724 & 15.790 \\
\hline Total & 771 & 1.738 .917 & 47.161 \\
\hline
\end{tabular}

Fonte: OCD (2019). Elaborado pelos autores.

*Estes 13 ramos foram reagrupados em março de 2019, formando, desde então, apenas 7 ramos (agropecuário; consumo; crédito; infraestrutura; saúde; trabalho e produção de bens e serviços; e, transporte).

Em Minas Gerais não foram identificadas cooperativas nos ramos: especial e turismo/lazer, apesar do grande potencial turístico do Estado. Os ramos agropecuário, crédito, transporte e saúde apresentaram maior quantidade de cooperativas; em número de cooperados o destaque é das cooperativas de crédito; o volume de emprego direto é maior nas cooperativas dos ramos agropecuário, saúde e de crédito.

A OCB (2019, p.18), destaca a importância da oferta de emprego nas cooperativas no Brasil:

\begin{abstract}
A população ocupada no Brasil cresceu 0,36\% de 2014 a 2018, com um saldo positivo de 340 mil postos de trabalho. No mesmo período, quando olhamos apenas os empregados no setor privado, houve uma queda de $5 \%$ no mesmo indicador, representando um saldo negativo de 2,3 milhões de postos de trabalho. O cooperativismo, entretanto, expandiu suas contratações entre 2014 e 2018 crescendo $17,8 \%$ e gerando um saldo positivo 64,3 mil vagas.
\end{abstract}

A mensuração se refere a geração de emprego direto, pois não tem como calcular a contratação indireta, fato é que as cooperativas impactam positivamente na composição da renda familiar de milhares de brasileiros. Independente do ramo, as cooperativas buscam aprimoramento investindo na ampliação e modernização, uma vez que existem diversos desafios 
comuns e específicos. Na sequência apresenta-se a área de estudo, onde predomina cooperativas agropecuárias.

\section{Caracterização dos municípios da Mesorregião Noroeste de Minas de Minas Gerais}

Existem muitas regionalizações do território mineiro, sendo as oficiais do IBGE e da FJP, para este artigo, optou-se pela Divisão regional do Brasil em mesorregiões e microrregiões geográficas do IBGE (1990), que regionaliza Minas Gerais em doze mesorregiões e 66 microrregiões. Especificamente a Mesorregião Noroeste de Minas compreende área de 62.401.100 km² e 19 municípios, distribuídos nas Microrregiões de Unaí e Paracatu.

A Microrregião de Paracatu abarca os municípios de Brasilândia de Minas, Guarda-Mor, João Pinheiro, Lagamar, Lagoa Grande, Paracatu, Presidente Olegário, São Gonçalo do Abaeté, Varjão de Minas e Vazante. A Microrregião de Unaí compreende os municípios de Arinos, Bonfinópolis de Minas, Buritis, Cabeceira Grande, Dom Bosco, Formoso, Uruana de Minas, Natalândia e Unaí (Figura 1).

No que tange a localização da Mesorregião Noroeste de Minas pode-se identificar que limita com municípios das Mesorregiões Norte de Minas, Central Mineira e Triângulo Mineiro/Alto do Paranaíba; além de municípios dos Estados da Bahia e Goiás, também limita com área do Distrito Federal. O raio de influência de Brasília - Distrito Federal é enorme nos municípios da Mesorregião Noroeste de Minas, inclusive Unaí, Buritis, Cabeceira Grande e Arinos fazem parte da Região Integrada de Desenvolvimento do Distrito Federal (RIDE-DF).

Os acessos aos municípios do Noroeste de Minas são por trechos das: BR 354; BR 251; BR 040 e MG 188. A BR 040 é o principal acesso a Belo Horizonte, a Brasília-Distrito Federal e para alguns municípios de Goiás. A Ferrovia Centro-Atlântica (FCA) se configura na principal via de transporte de grãos e fertilizantes do Noroeste de Minas, funciona como elo de ligação a municípios da Mesorregião Central-Mineira aos portos de Vitória e do Açu no Espírito Santo.

A principal bacia hidrográfica do Noroeste de Minas é a do rio São Francisco, mas não existe transporte por hidrovias e apesar do grande dinamismo agropecuário com forte rede de negócios a Mesorregião não conta com aeroporto comercial (FIEMG, 2017). De acordo com Federação das Indústrias do Estado de Minas Gerais (FIEMG, 2017, pp.20-21)

A rodovia BR-251 tem início no estado do Mato Grosso e estende-se até o estado da Bahia, com traçado no sentido oeste-leste e extensão total de $1.515 \mathrm{~km}$. No Noroeste de Minas, a rodovia alcança a extensão de $215 \mathrm{~km}$, entre a divisa de Goiás e Minas Gerais e a cidade de Brasilândia de Minas. Também na região, a BR-251 faz ligação entre Unaí, 
Boqueirão e Brasilândia de Minas e recebe o fluxo, principalmente, de Paracatu e Triângulo Mineiro, por meio da MG-188. [...] A rodovia BR-040 tem início em Brasília (DF) e ponto final localizado no Rio de Janeiro (RJ), com extensão de $1.179 \mathrm{~km}$. Na região Noroeste de Minas, a rodovia tem cerca de 280 km entre a divisa de Goiás e Minas Gerais e a cidade de Três Marias. Também na região, liga as cidades de Paracatu, João Pinheiro e Três Marias a Belo Horizonte e Sudeste do Brasil. A BR-040 tem relevância no Noroeste Mineiro, pois possibilita o escoamento das cadeias produtivas de Unaí, Paracatu, João Pinheiro e Brasilândia de Minas para as demais regiões do Sudeste. A MG-188 é uma rodovia longitudinal mineira, com extensão total de $390 \mathrm{~km}$, entre a divisa dos estados de Minas Gerais e Goiás e a cidade de Patrocínio/MG. Nas regiões do Alto Paranaíba e Noroeste de Minas, faz ligação entre Unaí-Paracatu-Guarda-Mor-Coromandel, com um total de $268 \mathrm{~km}$.

Figura 1 - Municípios por Microrregião do Noroeste de Minas - Minas Gerais.

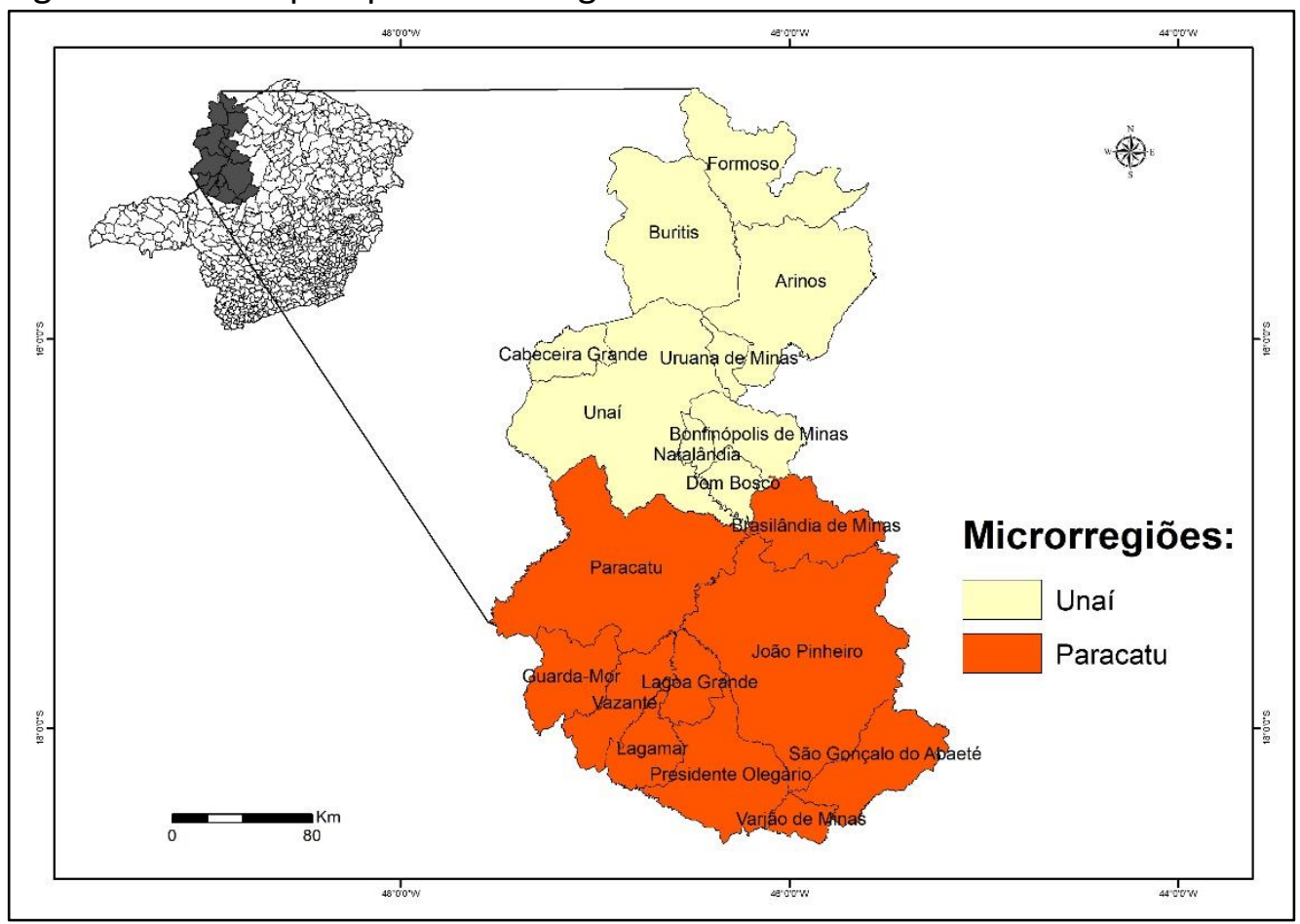

Fonte: IBGE, 2010. Org e cartografia: OLIVEIRA FILHO, E.R, 2021.

O principal objetivo da RIDE-DF é articular ações administrativas para dinamizar o desenvolvimento econômico da área de abrangência. A RIDE-DF foi institucionalizada por meio da Lei Complementar no 94/1998, regulamentada pelo Decreto № 2.710, de 04 de agosto de 1998. A Lei Complementar no 163 de 14 de junho de 2018 regulamentou a expansão da RIDE-DF que abrange o Distrito Federal, vinte e nove municípios de Goiás e quatro municípios de Minas Gerais.

Em relação a extensão territorial, pode-se afirmar que em geral os municípios do Noroeste de Minas são grandes, inclusive João Pinheiro é o maior do Estado; quanto ao ano de instalação a maioria emancipou na segunda metade do século XX (Tabela 3). A maioria dos municípios emancipou do território de Paracatu que apresenta importância histórica por ter sido 
palco do processo de interiorização nacional com a pecuária e posteriormente no século XVIII pelas descobertas das minas de ouro no vale do rio Paracatu.

A circulação do ouro na região do Paracatu e a movimentação intensa da população incentivaram o comércio local que foi favorecido pela confluência de importantes estradas [...]. O encontro das estradas que convergiam para essa região resultava em apenas uma via que se dirigia às minas goianas, possibilitando o intercâmbio entre Paracatu, principais regiões de Minas Gerais e Goiás (CARVALHO, 1992, p.42).

Tabela 3 - Ano de instalação e extensão territorial dos municípios do Noroeste de Minas

\begin{tabular}{lcr}
\hline Municípios & Ano de instalação & \multicolumn{1}{c}{ Área territorial } \\
\hline Paracatu & 1798 & $8.229,587 \mathrm{~km}^{2}$ \\
João Pinheiro & 1911 & $10.727,471 \mathrm{~km}^{2}$ \\
Presidente Olegário & 1938 & $3.503,848 \mathrm{~km}^{2}$ \\
Unaí & 1943 & $8.448,082 \mathrm{~km}^{2}$ \\
São Gonçalo do Abaeté & 1943 & $2.692,545 \mathrm{~km}^{2}$ \\
Vazante & 1953 & $1.913,396 \mathrm{~km}^{2}$ \\
Lagamar & 1962 & $1.474,562 \mathrm{~km}^{2}$ \\
Arinos & 1963 & $5.279,419 \mathrm{~km}^{2}$ \\
Buritis & 1963 & $5.225,186 \mathrm{~km}^{2}$ \\
Formoso & 1963 & $3.686,004 \mathrm{~km}^{2}$ \\
Brasilândia de Minas & 1963 & $2.509,694 \mathrm{~km}^{2}$ \\
Guarda-Mor & 1963 & $2.069,795 \mathrm{~km}^{2}$ \\
Bonfinópolis de Minas & 1963 & $1.850,487 \mathrm{~km}^{2}$ \\
Lagoa Grande & 1992 & $1.236,301 \mathrm{~km}^{2}$ \\
Cabeceira Grande & 1995 & $1.031,409 \mathrm{~km}^{2}$ \\
Dom Bosco & 1995 & $817,383 \mathrm{~km}^{2}$ \\
Varjão de Minas & 1995 & $651,505 \mathrm{~km}^{2}$ \\
Uruana de Minas & 1995 & $589,221 \mathrm{~km}^{2}$ \\
Natalândia & 1995 & $466,580 \mathrm{~km}^{2}$ \\
\hline Total & ----- & $62.402,48 \mathrm{~km}^{2}$ \\
\hline
\end{tabular}

Fonte: IBGE (2020). Elaborado pelos autores, 2021.

A descoberta de ouro oportunizou curta prosperidade da sociedade regional, mas o declínio da mineração no final do século XVIII levou o isolamento regional até a construção de Brasília-Distrito Federal. O longo período de isolamento, assim como as terras férteis e a disponibilidade de água favoreceram a formação de grandes propriedades rurais com elevada produção de grãos e criação de bovinos, mas com baixa densidade demográfica (Figura 2).

O IBGE (2010), recenseou 366.418 habitantes, a maioria reside na área urbana (286.618 habitantes), no espaço rural foi registrado 79.800 pessoas (Figura 2). Existe desigual distribuição da população concentrada em Paracatu (84.718 habitantes), Unaí (77.565 pessoas) e João Pinheiro (45.260 habitantes); os municípios com menor população emanciparam na década de 1990, sendo: Uruana de Minas (3.235 habitantes); Natalândia (3.280 habitantes) e Dom Bosco 


\section{(3.814 habitantes).}

Em função da pandemia da Corona Virus Disease 19 (COVID-19), o Censo Demográfico de 2020 foi adiado para 2021. De acordo com o IBGE (2020), as estimativas indicam para o Noroeste de Minas um total de 381.780 pessoas, apontaram também mesmo número de habitantes do Censo de 2010 em Lagamar; reduções em Bonfinópolis de Minas e Dom Bosco; inexpressivo crescimento nos munícipios de Guarda-Mor (quatro habitantes), de Uruana de Minas (vinte e cinco habitantes) e de Natalândia (vinte e oito habitantes).

Figura 2 - População total, rural e urbana do Noroeste de Minas - Minas Gerais.

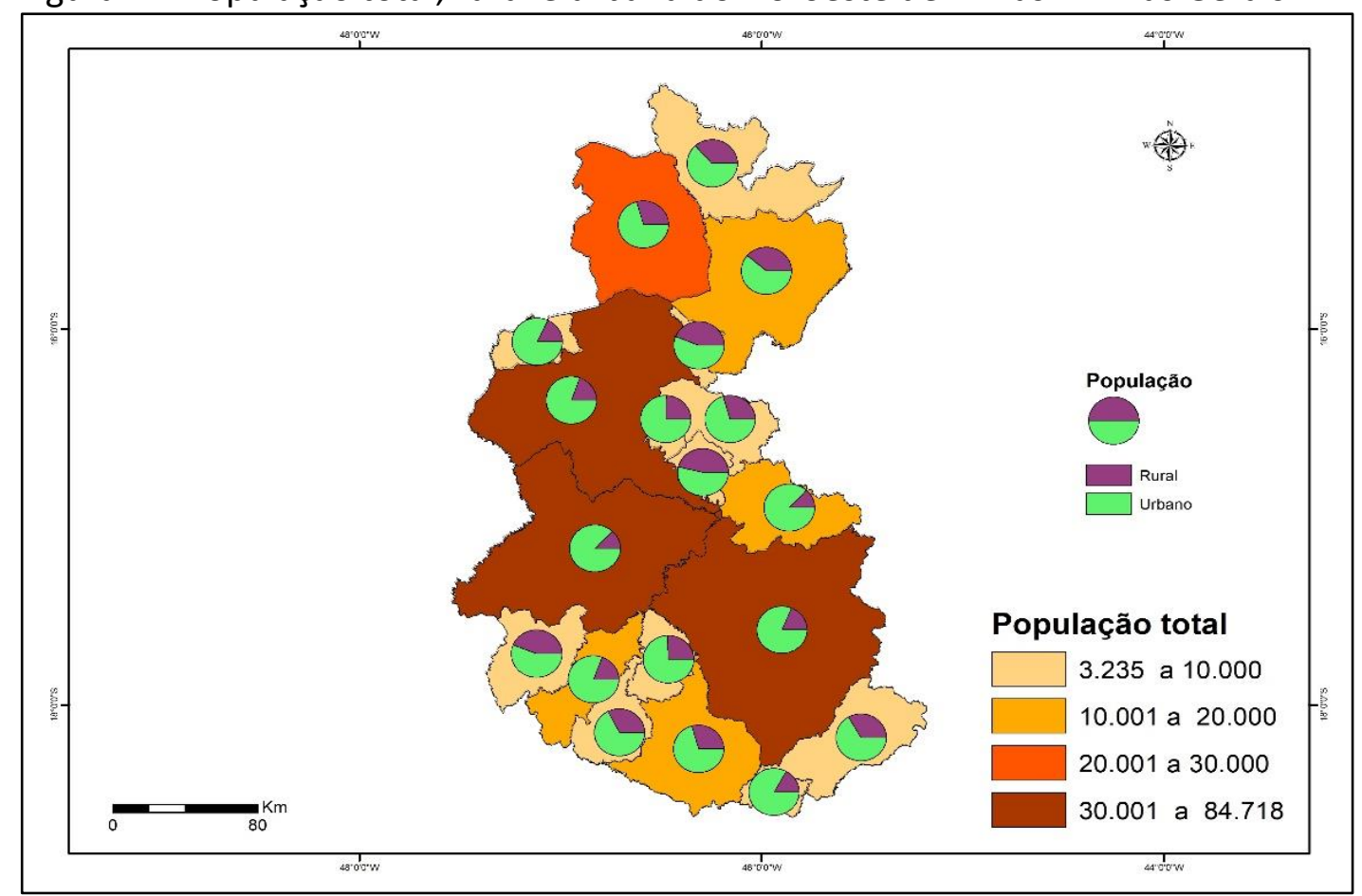

Fonte: IBGE, Censo 2010. Org e cartografia: OLIVEIRA FILHO, E.R, 2021.

Por se tratar de uma Mesorregião com grandes propriedades rurais modernas, a atração populacional é reduzida, pois não há muita oferta de trabalho manual, quase todas as atividades são realizadas por máquinas. As estimativas refletem também a queda da taxa de fecundidade total, realidade de vários municípios do Brasil, no caso de Minas Gerais, Ferreira et al (2012, p.79), apontam:

A médio e longo prazos, do ponto de vista populacional, o estado de Minas Gerais se deparará com uma questão que há trinta anos seria inimaginável, o despovoamento de regiões. Considera-se que a partir de 2040 a população estadual começará a diminuir. Esse fenômeno já acontecerá anos antes em algumas regiões. Tal fato gera uma série de impactos sociais, geográficos e econômicos já observáveis em países europeus. Entre eles, a falta de mão de obra em idade ativa, redução da capacidade empreendedora e ociosidade de infraestrutura. 
Em relação à dinâmica econômica, conforme a FJP; DIREI (2018), a agropecuária tem expressiva participação no PIB dos municípios do Noroeste de Minas, com maior destaque para Unaí, Paracatu, João Pinheiro e Buritis. Conforme a FIEMG (2017, p 22), o Noroeste de Minas,

[...] apresenta economia altamente agrícola, com destaque para a produção de milho e soja, assim como para a criação de gado em pé, com foco nas cidades de Unaí, Paracatu e João Pinheiro. As três cidades foram responsáveis pela produção de 919 mil cabeças de gado em 2012 (Sudeste Competitivo, 2014 ${ }^{1}$ ), equivalente a 2,5\% de toda a produção do Sudeste brasileiro no mesmo ano. Também em 2012, a produção de milho em grãos do Noroeste de Minas foi de 1,45 milhão de toneladas, sendo $89 \%$ deste montante escoado por rodovias para outras regiões do estado de Minas Gerais e $7 \%$ consumido localmente. Já a produção de soja em grãos foi de 1,15 milhão de toneladas em 2012, sendo $78 \%$ deste total escoado por rodovia para o Triângulo Mineiro e $20 \%$ enviado para o exterior (Sudeste Competitivo, 2014), por meio do modal ferroviário.

Neste estudo apresenta-se os Valores Adicionados Bruto (VABs) da agropecuária no PIB a preços correntes de 2017, os dados foram publicados em 2020. Os dados expressam o panorama de diferença do PIB a preço corrente entre os munícipios da Mesorregião Noroeste de Minas, sendo que a soma de João Pinheiro e Unaí supera o PIB dos demais municípios, exceto Paracatu. O PIB de Paracatu é igual à soma de 16 municípios, exceto de Unaí e João Pinheiro (Tabela 4).

Tabela 4 - VAB da agropecuária e PIB municipal (preços correntes) no Noroeste de Minas (2017)

\begin{tabular}{lrr}
\hline Municípios & PIB (1000 R\$) & VAB (1000 R\$) \\
\hline Natalândia & 43.844 .840 & 7.089 .930 \\
Uruana de Minas & 50.450 .310 & 14.317 .760 \\
Dom Bosco & 50.496 .010 & 13.789 .620 \\
Formoso & 154.807 .180 & 56.227 .870 \\
Varjão de Minas & 181.962 .080 & 89.461 .870 \\
Cabeceira Grande & 182.247 .640 & 69.050 .300 \\
Bonfinópolis de Minas & $201.430,830$ & $110.724,420$ \\
Arinos & 205.425 .110 & 40.624 .200 \\
São Gonçalo do Abaeté & 211.330 .630 & 49.366 .170 \\
Brasilândia de Minas & 219.226 .410 & 39.397 .290 \\
Lagoa Grande & 228.081 .710 & 61.934 .640 \\
Lagamar & 262.695 .580 & 43.746 .800 \\
Guarda-Mor & 340.183 .160 & 181.815 .360 \\
Presidente Olegário & 454.113 .760 & 188.158 .490 \\
Vazante & 644.829 .190 & 101.585 .400 \\
Buritis & 700.922 .360 & 260.569 .630 \\
João Pinheiro & 1.461 .889 .360 & 374.092 .990 \\
Unaí & 2.676 .152 .480 & 706.072 .960 \\
Paracatu & 3.510 .747 .530 & 600.047 .530 \\
\hline Total & 11.579 .606 .771 & 2.897 .459 .534 \\
\hline
\end{tabular}

Fonte: FJP; DIREI (2020). Elaborado pelos autores, 2021.

1 Projeto Sudeste Competitivo, Macrologística e Confederação Nacional da Indústria (CNI). Junho de 2014 (nota da referência). 
As fazendas na Mesorregião Noroeste de Minas são produtoras de grãos de milho, soja, feijão, em geral são imensas áreas com irrigada por pivô central; além dos pastos para criação de bovinos de corte e leiteiro, portanto o setor agropecuário prevalece como base da economia regional. O sistema produtivo é altamente tecnológico com extensa rede de irrigação que se destaca no cenário nacional, pois integra os principias polos com uso de pivôs centrais.

\begin{abstract}
Os polos de irrigação do São Marcos e do Paracatu-Entre Ribeiros são vizinhos, envolvendo porções do território dos mesmos municípios principais: Unaí/MG, Paracatu MG e Cristalina/GO - maiores irrigantes por pivôs do Brasil, além de Guarda--Mor/MG. Ou seja, nestes municípios os pivôs estão distribuídos entre os divisores de águas das Regiões Hidrográficas São Francisco (sub-bacia do rio Paracatu) e Paraná (sub-bacia do rio São Marcos, afluente do Paranaíba). No Alto São Marcos também possuem áreas expressivas de pivôs os municípios goianos de Campo Alegre de Goiás, Luziânia, Ipameri e Catalão; e no Alto Paracatu-Entre Ribeiros os municípios mineiros de Brasilândia de Minas e Bonfinópolis de Minas, além de Brasília/DF (BRASIL, 2019, p.33).
\end{abstract}

Na Mesorregião Noroeste de Minas também existem pequenos e médios produtores que permanecem utilizando técnicas de produção com menor ou nenhum uso das novas tecnologias aplicadas ao campo, assim como agricultores dos assentamentos rurais regulamentados pelo Instituto Nacional de Colonização e Reforma Agrária (Incra). Todo o arranjo produtivo favorece a expansão e fortalecimento das cooperativas, apesar das adversidades enfrentadas. Sobre os desafios e oportunidades do ramo agropecuário, independentemente da localização geográfica, a $\operatorname{OCD}(2019$, p.38), aponta:

\begin{abstract}
O trabalho sistêmico para os próximos ciclos deve priorizar a busca constante de um ambiente favorável à atuação das cooperativas agropecuárias dos pontos de vista jurídico, tributário e regulatório, assim como o fortalecimento da imagem que a sociedade, incluindo governantes, tomadores de decisão e órgãos de comunicação, têm em relação as cooperativas e os seus modelos de negócio. Os principais eixos a serem trabalhados pelo ramo, de forma global, são ainda um maior acesso ao crédito e linhas de financiamento público para as cooperativas, o seguro rural, a garantia de renda ao produtor rural e a regularidade de abastecimento, o acesso a mercados, infraestrutura e logística, e a participação das cooperativas nas contratações públicas, este último com forte priorização do Sistema OCB que desenvolveu em 2018 uma importante ferramenta para facilitar a participação de cooperativas em compras públicas.
\end{abstract}

No Noroeste de Minas existem várias cooperativas com predomínio do setor agropecuário, na sequência apresenta-se cinco delas.

\title{
3 Perfil das cooperativas do ramo agropecuário do Noroeste de Minas
}

A pesquisa que deu origem a este artigo é um estudo de caso comparativo utilizando os dados de cinco das cooperativas do Noroeste de Minas: a Cooperativa Agropecuária do Vale do 
Paracatu (COOPERVAP), a Cooperativa Agropecuária de Unaí Ltda (CAPUL), a Cooperativa Agrícola de Unaí Ltda (COAGRIL), a Cooperativa de Agricultura Familiar Sustentável com Base na Economia Solidária Ltda (COPABASE) e a Cooperativa Mista dos Assentados e Agricultores Familiares do Noroeste de Minas (COOPERFAN).

A COOPERVAP foi fundada em 1963 por quarenta agricultores, sendo a primeira cooperativa agropecuária de Paracatu, desde então expandiu e se tornou potência regional com elevado faturamento anual, "[...] mais de 180 milhões de reais, o quadro social é formado por mais de 2 mil associados, a cooperativa emprega 500 funcionários diretos, é fonte de renda para o estado e município gerando mais de 22 milhões de reais em Tributos e encargos sociais" (COOPERVAP, $2021 \mathrm{~s} / \mathrm{n}$ ㅇ) $)$

A geração de empregos e o faturamento da COOPERVAP são indicativos da importância local e regional. A COOPERVAP exerce papel social importante com ações e projetos que favorecem aos cooperados e entidades filantrópicas através de patrocínios, arrecadação e doação de alimentos. Uma Cooperativa reconhecida pela qualidade, ética, parcerias que impulsiona desenvolvimento, integração com o público, profissionalização, liderança e compromisso socioambiental.

O crescimento da COOPERVAP oportunizou o fortalecimento do cooperativismo e aquisição de infraestrutura para cooperados e parceiros. Assim têm-se: uma Fábrica de Laticínios; uma Fábrica de Suplementos Minerais; uma loja Comercial Agrícola que vende sementes, adubos e defensivos agrícolas; duas unidades certificadas de armazenamento, classificação, padronização, beneficiamento, industrialização e comercialização de arroz, feijão, soja, sorgo, milho e café; uma Loja Veterinária e dois Postos de Combustíveis. Além de Hipermercado com açougue, lanchonete, loja de confeç̧ões e sessão de hortifrúti; uma Unidade de Indústria Láctea responsável pela fabricação dos Produtos Paracatu comercializados em várias Unidades da Federação. Dentre os Produtos Paracatu pode-se elencar: queijos, manteiga, doce de leite, iogurte, requeijão cremoso e em barra, entre outros (COOPERVAP, 2021).

No que se refere a CAPUL foi fundada em 1964 no município de Unaí, iniciou com oitenta associados e em 2021 conta com mais de três mil cooperados e vários parceiros.

São mais de 3000 mil cooperados ativos e mais de 800 colaboradores [...] atua em diversas áreas ligadas direta e indiretamente ao agronegócio. Através de suas atividades, atende as necessidades dos cooperados, de seus familiares e demais clientes. Sua área comercial abrange desde produtos veterinários, peças e ferragens, tanques de Leite, silos, postos de combustíveis automotores, supermercados, rações e suplementos minerais. Dentre os serviços que presta ao produtor rural cooperado, encontram-se: assistência técnica rural especializada; assessoria ambiental; 
manutenção mecânica e elétrica; consultoria jurídica, administrativa e financeira (CAPUL, 2021, s/nㅇ).

Ao longo do tempo foram realizadas mudanças estruturais que fortaleceram as ações oportunizando a expansão da CAPUL que abrange municípios de Minas Gerais (Mesorregiões Norte de Minas e Noroeste de Minas) e um município do Estado de Goiás. Da Mesorregião Noroeste de Minas têm-se: Unaí, Arinos, Bonfinópolis de Minas, Brasilândia de Minas, Buritis, Cabeceira Grande, Dom Bosco, Natalândia e Uruana de Minas; os municípios de Riachinho e Urucuia ficam na Mesorregião Norte de Minas e o município de Cabeceiras que integra o Estado de Goiás (Figura 3).

Figura 3 - Área de abrangência da CAPUL em Minas Gerais e Goiás

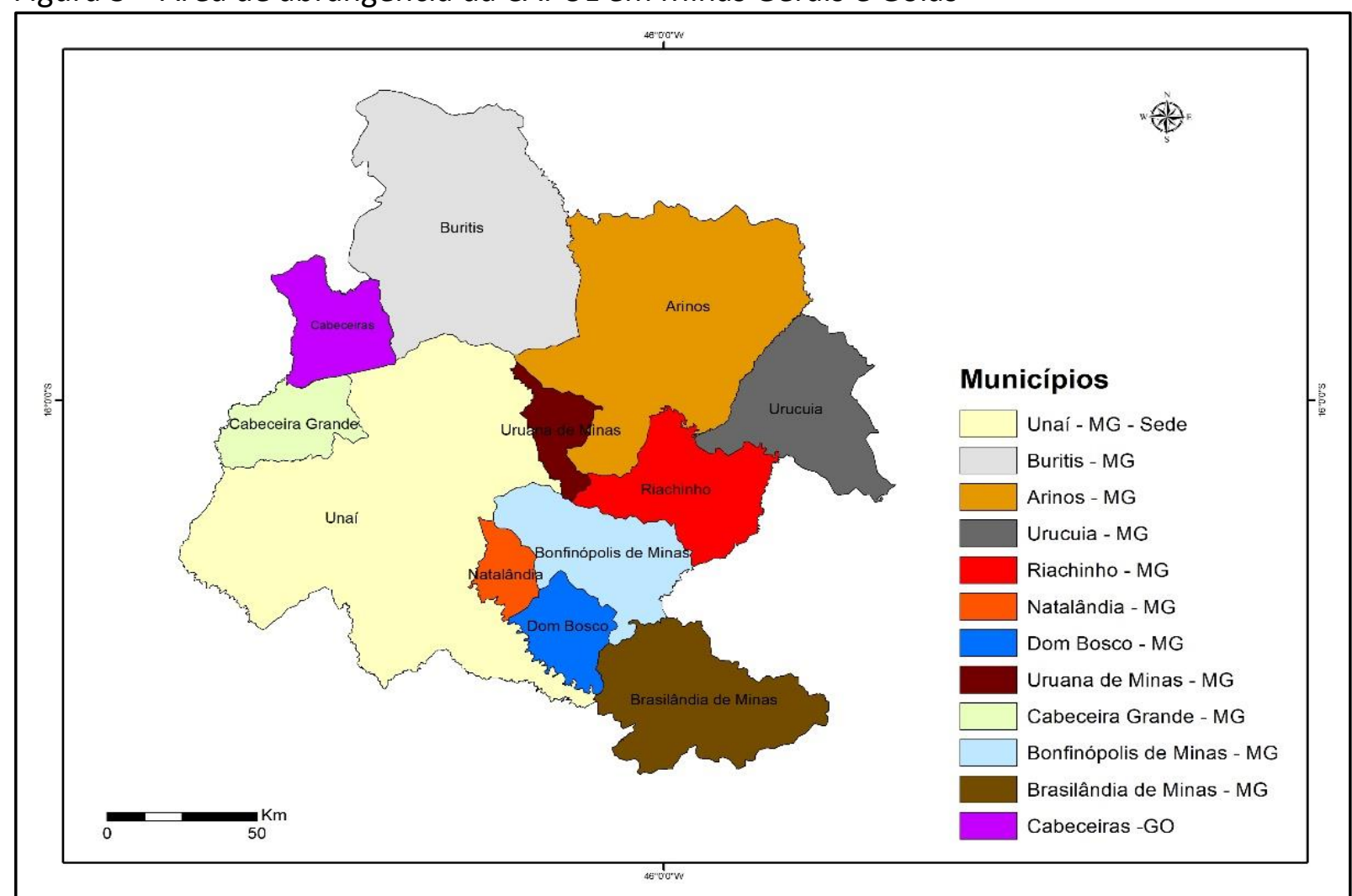

Fonte: CAPUL, 2020. Org e cartografia: OLIVEIRA FILHO, E.R, 2021.

A CAPUL valoriza o cooperativismo e a força do trabalho, razão pela qual tem expandido e comercializado seus produtos em outras Unidades da Federação, além de Minas Gerais. São vários projetos para tender a dinâmica econômica do mercado, que confirmam a importância da CAPUL (Quadro 1). 
Quadro 1 - Descrição dos projetos da CAPUL

\begin{tabular}{|c|c|}
\hline Projetos & Descrição \\
\hline $\begin{array}{l}\text { Assistência } \\
\text { agronômica }\end{array}$ & $\begin{array}{l}\text { A cooperativa disponibiliza serviços agronômicos gratuitos ao cooperado. Os } \\
\text { profissionais realizam coleta de amostra de solo, recomendações de calagem e } \\
\text { adubação, projetos para produção de grãos, projeto de irrigação e acompanhamentos } \\
\text { de lavouras. }\end{array}$ \\
\hline $\begin{array}{l}\text { Comitês } \\
\text { Educativos }\end{array}$ & $\begin{array}{l}\text { O objetivo do Comitê Educativo é difundir entre os cooperados os princípios do } \\
\text { cooperativismo, sua história e filosofia. Além de promover a cooperativa, orientar } \\
\text { cooperados da comunidade com relação às operações e serviços, ser o meio de } \\
\text { comunicação dos cooperados com a administração da CAPUL e vice-versa, levar à } \\
\text { administração as aspirações, opiniões, pareceres dos cooperados sobre a atuação da } \\
\text { cooperativa, entre outras. }\end{array}$ \\
\hline $\begin{array}{l}\text { Assistência } \\
\text { para as } \\
\text { associações }\end{array}$ & $\begin{array}{l}\text { Cada associação cooperada, que realize movimentações financeiras com a cooperativa } \\
\text { e seja fornecedora de Leite, terá a oportunidade de indicar um sócio da associação para } \\
\text { receber assistência de um médico veterinário ou técnico mensalmente e servir de } \\
\text { unidade demonstrativa. Não tendo qualquer custo a ser pago pelo produtor ou pela } \\
\text { associação }\end{array}$ \\
\hline $\begin{array}{l}\text { Frango } \\
\text { Caipira }\end{array}$ & $\begin{array}{l}\text { O Projeto do Frango Caipira CAPUL vem para agregar valor às atividades do cooperado } \\
\text { da cooperativa. Funciona da seguinte forma, a cooperativa compra o frango direto do } \\
\text { produtor, abate as aves num abatedouro certificado, e coloca o produto à venda nos } \\
\text { supermercados com o selo de garantia. Os produtores que fazem parte do projeto } \\
\text { recebem assistência técnica especializada da cooperativa. }\end{array}$ \\
\hline $\begin{array}{l}\text { Café } \\
\text { Conilon }\end{array}$ & $\begin{array}{l}\text { A fim de viabilizar a diversificação das atividades do seu cooperado começa a estudar a } \\
\text { possibilidade de introdução do café Conilon na região do noroeste mineiro. Pois, acredita } \\
\text { que pode ser um bom negócio para produtor, e que possa surgir uma combinação dentro } \\
\text { das propriedades com outras atividades como Leite, maracujá, frango caipira. Para testar } \\
\text { fez um pequeno plantio irrigado por gotejamento, na Chácara da CAPUL, em uma área } \\
\text { de } 0,8 \text { ha. Aproximadamente } 3.600 \text { mudas de } 14 \text { clones diferentes. Os materiais foram } \\
\text { identificados e o departamento técnico, irá monitorar a lavoura, para observar o e } \\
\text { ataque de pragas, doenças, e resistência de cada clone ao clima da região. }\end{array}$ \\
\hline Maracujá & $\begin{array}{l}\text { A fim de em viabilizar novas atividades para os produtores rurais da região que tenham } \\
\text { interesse em agregar valor à renda da família. Foi feito parceria com Empresa Brasileira } \\
\text { de Bebidas e Alimentos (EBBA) que oferece a comercialização garantida, assistência } \\
\text { técnica especializada, mudas de qualidade a preços especiais, Logística de transporte } \\
\text { sem custo, fornecimento de embalagens, garantia de pagamento, preço mínimo } \\
\text { garantido aos produtores de maracujá. Além da assistência técnica da empresa EBBA a } \\
\text { CAPUL disponibiliza assistência técnica gratuita aos cooperados interessados em plantar } \\
\text { o maracujá. }\end{array}$ \\
\hline Leite & $\begin{array}{l}\text { O cooperado fornecedor de leite, para qualquer indústria pode ser atendido pela equipe } \\
\text { técnica do Assistência Técnica e Extensão Rural (ATER) Leite conta com a visita mensal } \\
\text { de um técnico e a cada } 60 \text { dias a assessoria de um médico veterinário, que fará o controle } \\
\text { reprodutivo do rebanho leiteiro. O custo pago pelo produtor é somente a } \\
\text { quilometragem rodada pelo veterinário. }\end{array}$ \\
\hline $\begin{array}{l}\text { Legalização } \\
\text { da } \\
\text { produção }\end{array}$ & $\begin{array}{l}\text { A CAPUL incentiva a diversificação de produção e viabiliza a comercialização da produção } \\
\text { dos cooperados. Para o produtor comercializar produtos processados como rapadura, } \\
\text { farinha, doce, biscoitos, ovos, queijo, entre outros é necessário um alvará sanitário ou o } \\
\text { selo de inspeção municipal. A cooperativa tem incentivado essa legalização e apoiado os } \\
\text { produtores interessados para produzir alimentos com segurança e qualidade. }\end{array}$ \\
\hline
\end{tabular}

Fonte: CAPUL, 2021, s/no. Org e adaptação: OLIVEIRA FILHO, E.R, 2021. 
Quanto ao perfil dos cooperados são pequenos, médios e grandes produtores dos munícipios da área de abrangência, que contam como fábricas de laticínios, ração e suplementos minerais; rede de supermercados; lojas de produtos veterinários, agropecuários, rações e insumos. As Lojas Agroveterinárias ficam na sede (Unaí) e nas filiais em: Bonfinópolis de Minas, Brasilândia de Minas, Buritis, Cabeceira Grande, Dom Bosco, Riachinho, Arinos, Urucuia, Natalândia e Uruana de Minas e Cabeceiras. Em Unaí têm-se Lojas de Combustíveis e Lubrificantes, Fábricas de Laticínios, Indústria de Nutrição Animal, Sistema de Transporte e Oficina Elétrica e Mecânica. A cooperativa conta também com Postos de Combustíveis em Arinos e Unaí, além de Supermercados em Unaí, Arinos, Buritis, Cabeceira Grande e Dom Bosco (CAPUL, 2021).

Com relação à COAGRIL, os excelentes resultados conferiram a esta cooperativa, em 2019, a criação de um Departamento Comercial de Feijão, além de várias certificações: Nespresso, Starbucks, 4C Association, UTZ, Região do Cerrado Mineiro, Empresa Cidadã, entre outras. A COAGRIL foi eleita pela Revista Globo Rural a Melhor Cooperativa do Agronegócio em Minas Gerais, ficando entre as dez melhores do Brasil e entre as quinhentas do mundo Agro. A COAGRIL tem sede em Unaí e uma filial no município de Formoso no Estado de Goiás, abrange a área do Distrito Federal, de outros municípios de Minas Gerais e Goiás, além de cooperados da Bahia e Mato Grosso, conta com mais de trezentos cooperados (COAGRIL, 2021).

Dados de 2019 apontam que COAGRIL faturou aproximadamente 1,3 bilhão de reais, sendo: 322 milhões de reais obtidos pelo Programa de Redução de Custo com Qualidade (PROAGRIL) e 974 milhões de reais no faturamento de grãos, uma vez que foram comercializadas mais de um milhão de toneladas de grãos (COAGRIL, 2021). Tais informações apontam que apesar da crise econômica do Brasil, a referida Cooperativa apresentou ótimo resultado, assim como vários segmentos do agronegócio.

Os armazéns e silos da COAGRIL tem sistema de alta tecnologia com termometria computadorizado e aeração para controle de temperatura dos estoques, além de contar com profissionais qualificados. A Cooperativa desenvolve ações sociais como doação de feijão para intuições, financiamento de bolsas de estudo, além de parcerias com o Instituto Nacional de Processamento de Embalagens (INPEV), para reciclagem de embalagens de defensivos agrícolas, entre outras.

Quanto a COPABASE foi fundada em 2008, no município de Arinos com apoio de vários parceiros, dentre eles pode-se elencar: a Agência de Desenvolvimento Integrado e Sustentável do Vale do Rio Urucuia (ADISVRU); o Instituto Federal de Educação, Ciência e Tecnologia do Norte 
de Minas Gerais (IFNMG) - Campus Arinos; o Serviço Brasileiro de Apoio às Micro e Pequenas Empresas de Minas Gerais (SEBRAE-MG); a Universidade de Brasília (UNB) e a Fundação do Banco do Brasil (FBB).

A referida Cooperativa ao contrário da CAPUL, COOPERVAP e da COAGRIL tem o diferencial quanto a origem dos cooperados, pois são extrativistas, assentados e pequenos produtores rurais. A COPABASE iniciou com 43 cooperados e em 2021 conta com duzentos, apresenta objetivos amplos: fortalecer, beneficiar e comercializar produtos da agricultura familiar; organizar as cadeias produtivas de grupos familiares de pequenos agricultores com Declaração de Aptidão ao Programa Nacional de Fortalecimento da Agricultura Familiar (DAP), extrativistas e assentados.

Assim, pode-se apontar que a COPABASE exerce papel econômico e socioambiental, representa inclusão de indivíduos que tiveram oportunidades suprimidas pelo sistema produtivo altamente competitivo e desigual. Gera empregos diretos e indiretos na concepção da economia solidária que para Souza $(2000$, p. 7): tem “[...] pouco peso econômico, mas possuem grande significação cultural, afinal são experiências destacadamente educativas".

A COPABASE no intuito de revitalizar áreas degradadas desenvolve projetos de construção de barraginhas. Barros; Ribeiro (2009, p.32), apontam as vantagens das barraginhas:

\footnotetext{
- Ao conter as enxurradas, as barraginhas reduzem a erosão, o assoreamento e amenizam as enchentes.

- Ao colher a água da chuva, essas barraginhas proporcionam condições para que a água nelas represada se infiltre no solo, atingindo o lençol freático. Depois que a água se infiltra por completo, o lençol freático tem seu volume aumentado e a barraginha está pronta para receber as águas das próximas chuvas. Esse processo se repetirá sucessivamente em todo o ciclo chuvoso. Com isso, surgem minadouros e cacimbas, e os mananciais mantenedores das nascentes e córregos se fortalecerão.

- As barraginhas umedecem as baixadas, proporcionando uma agricultura segura e alimentos de qualidade, além de gerar emprego e renda.
}

As barraginhas funcionam como alternativas no enfrentamento de erosões, revitalização de nascentes, para contenção de água da chuvas, entre outros benefícios. A COPABASE também desenvolve programas para sensibilizar a população como descartar o lixo nas comunidades rurais, uma vez que não existe coleta e os danos são preocupantes. A COPABASE abrange os municípios de Arinos, Bonfinópolis de Minas, Buritis, Formoso, Natalândia, Uruana de Minas de Minas (Noroeste de Minas); além dos municípios de Pintópolis, Riachinho e Urucuia que integram a Mesorregião Norte de Minas (Figura 4). A sede da COPABASE fica no Campus Arinos do IFNMG. 
A produção da COPABASE se configura em menor quantidade do que as outras cooperativas regionais, além de fazer menor uso de tecnologias, mas de enorme importância, uma vez que priorizam a sustentabilidade do cerrado, produtos orgânicos, valorização da cultural regional, entre outras características. Assim, têm-se a produção de: açafrão, açúcar mascavo, farinha de mandioca, pólen, urucum, processamento da castanha de baru, de polpas de frutas tropicais do cerrado e mel de abelha. As polpas e o mel foram regulamentados pelo Ministério da Agricultura com o Sistema de Inspeção Federal (SIF), certificação que representa agregar valor aos produtos que atendem aos padrões de qualidade, normas e orientações de higiene e padronização. Outro importante segmento é o artesanato produzido e comercializado em pontos de vendas por várias artesãs (COPABASE, 2021).

Figura 4 - Municípios de abrangência da COPABASE

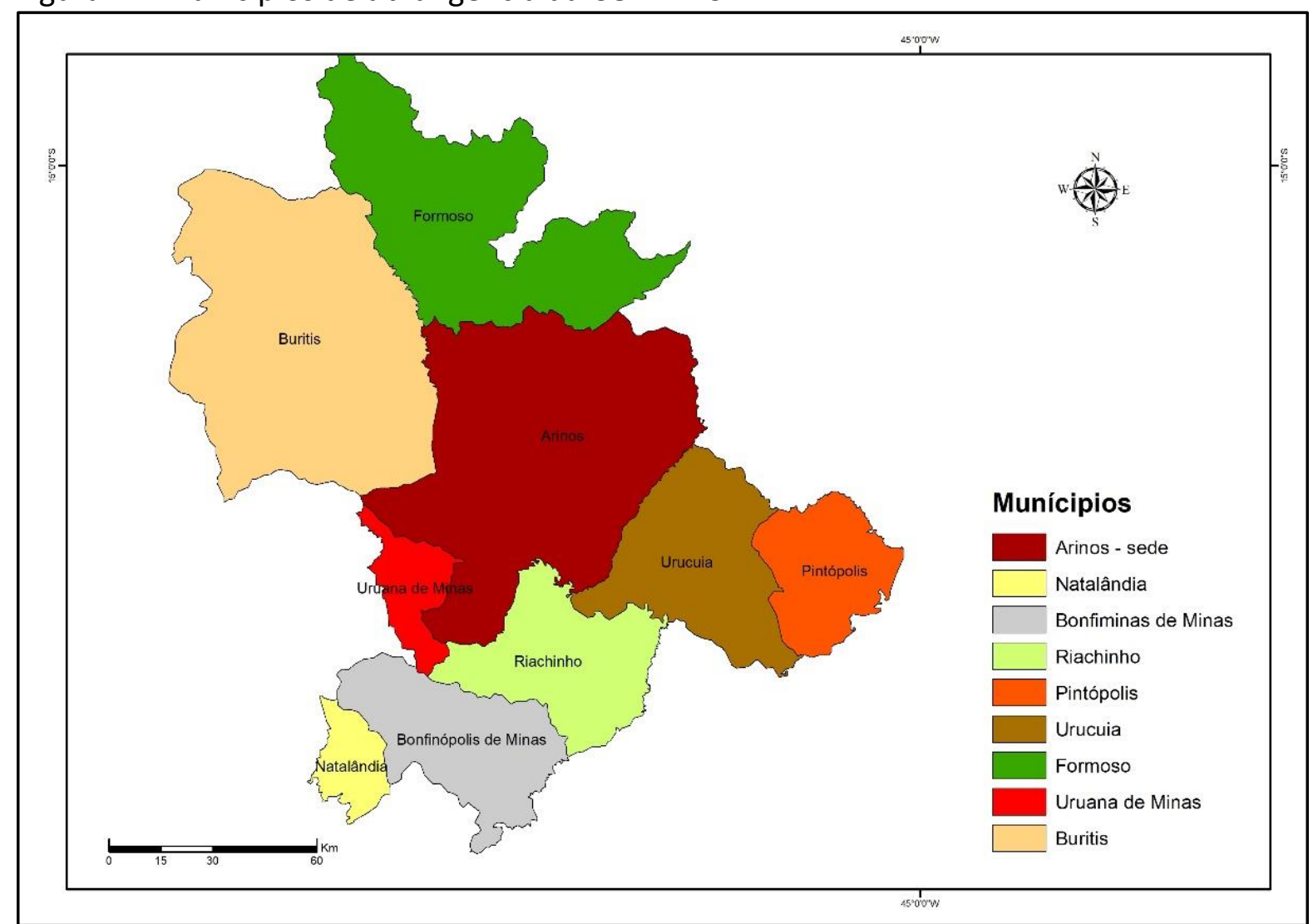

Fonte: COPABASE, 2021. Org e cartografia: OLIVEIRA FILHO, E.R, 2021

Quanto a COOPERFAN, foi fundada em 2010 no município de Paracatu, cujo objetivo foi e continua sendo desenvolver ações que fortaleçam a agricultura de produtores de assentamentos regulamentados pelo INCRA no âmbito regional. Até o encerramento deste estudo, contava com 180 cooperados dos municípios de Paracatu, Dom Bosco, Natalândia, Vazante, Guarda Mor, Unaí e João Pinheiro, que produzem frutas, legumes, verduras orgânicas, 
além de processar polpas de frutas do cerrado como cagaita e mangaba, mas o principal produto é a comercialização da castanha do baru (CENTRAL DO CERRADO, 2021).

As cooperativas descritas suprem demandas dos municípios da Mesorregião Noroeste de Minas e de outras localidades, especialmente na geração de postos de trabalho que consequentemente complementa a renda ou se torna a principal renda de várias famílias. Podese, portanto afirmar que elas se configuram em organizações de exercício de poder, onde os indivíduos buscam a inserção no intuito de colaborar e desfrutar dos benefícios.

\section{Considerações finais}

As cooperativas, independente, do ramo que atuam são fundamentais para dinamizar a economia. Ao analisar o levantamento da OCB da distribuição das cooperativas pelo território nacional, em 2018, identificou-se maior número na Região Sudeste, especialmente em São Paulo e Minas Gerais, apesar de prevalecer mais cooperados na Região Sul. Em 2018, no Estado de Minas Gerais foi registrado maior número de cooperativas agropecuárias, essas geram muitos postos de emprego e apresentam significativa quantidade de cooperados, superadas apenas pelas cooperativas de crédito.

Especificamente a Mesorregião Noroeste de Minas abarca munícipios, a exemplo, de Paracatu, Unaí, João Pinheiro, Buritis, que se destacam com fazendas altamente modernas no setor tecnológico com elevada produção de grãos e produtos derivados de leite. Também existem pequenas e médias propriedades nos referidos municípios e nos outros da Mesorregião, que contribuem para a dinâmica econômica. Características que favorecem para a consolidação das cooperativas agropecuárias com expansão além do limite regional e das fronteiras de Minas Gerais.

A COPABASE, por exemplo, foi fundada com intuito de atender pequenos produtores, extrativistas e agricultores de assentamentos, busca fortalecer as ações melhorando a vida de diversas famílias, principalmente com a economia solidária. Essa característica é marcante nas cooperativas que englobam indivíduos de baixa renda, portanto o cooperativismo tende a agregar valor aos produtos e favorecer a competição no mercado.

Deve-se destacar também a COOPERFAN que foi criada para atender os cooperados de assentamentos rurais, que necessitam do cooperativismo para dinamizar a comercialização de seus produtos. A COOPERVAP, a CAPUL e a COAGRIL são cooperativas com maior estrutura, na Mesorregião Noroeste de Minas, voltadas para atender produtores do agronegócio. Todas em 
geral, dispõem de expressiva infraestrutura com oferta de produtos e serviços de qualidade. Conclui-se, portanto que as cooperativas apresentadas são responsáveis por importantes atividades produtivas e contribuem para ampliar os arranjos produtivos, impactando favoravelmente na economia regional, estadual e nacional.

\section{Referências}

BARROS, L. C.; RIBEIRO, P. E. de A. Barraginhas: água de chuva para todos. Brasília (DF): Embrapa Informação Tecnológica, 2009. 49 p.

BRASIL. AGÊNCIA NACIONAL DE ÁGUAS. Levantamento da agricultura irrigada por pivôs centrais no Brasil. Brasília(DF): ANA, 2019. 49 p.

CAPUL. COOPERATIVA AGROPECUÁRIA DE UNAÍ LTDA. Dados da CAPUL. 2021. Disponível em <http://capul.coop.br/institucional/a-cooperativa/>. Acesso em 09/01/2021.

CARVAlho, M. da C. A. M. de. Paracatu: Morro do Ouro. São Paulo, Ed. Abril S. A., 1992. 66 p.

CENTRAL DO CERRADO. Dados da COOPERFAN. 2021. Disponível em <https://www.centraldocerrado.org.br/> . Acesso em 14/01/2021.

COAGRIL. COOPERATIVA AGRÍCOLA DE UNAÍ. Relatório anual 2019. 2021. Disponível em << https://www.coagril.coop.br/relatorio-anual-2019/>>. Acesso em 01/01/2021.

COOPERVAP. COOPERATIVA AGROPECUÁRIA DO VALE DO PARACATU. Dados da COOPERVAP. 2021. Disponível em <<http://www.coopervap.com.br/>>. Acesso em 14/01/2021

COPABASE. COOPERATIVA DE AGRICULTURA FAMILIAR SUSTENTÁVEL COM BASE NA ECONOMIA SOLIDÁRIA LTDA. Dados da COPABASE. 2021. Disponível em 《< <https://www.copabase.org/>. Acesso em 10/01/2020.

IBGE. INSTITUTO BRASILEIRO DE GEOGRAFIA E ESTATÍSTICA. Divisão regional do Brasil em mesorregiões e microrregiões geográficas. Rio de Janeiro, 1990. Disponível em: <http://biblioteca.ibge.gov.br/>. Acesso: 05/01/2021.

. Censo Demográfico de 2010. Rio de Janeiro (RJ): IBGE, 2010.

. Estimativas da população de 2020, área e ano de instalação do Noroeste de Minas. 2020. Disponível em <<https://cidades.ibge.gov.br/>. Acesso: 05/01/2021

FERREIRA, F. P. M.; et al. População e políticas públicas: tendências e cenários para Minas Gerais. IN. Cadernos BDMG. Belo Horizonte (MG): BDMG, n. 21, p. 55-85, out. 2012.

FEDERAÇÃO DAS INDÚSTRIAS DO ESTADO DE MINAS GERAIS - FIEMG. Perspectivas de desenvolvimento socioeconômico do Alto Paranaíba e Noroeste de Minas Gerais. Belo Horizonte: FIENMG, 2017.

FUNDAÇÃO JOÃO PINHEIRO - FJP. DIRETORIA DE ESTATÍSTICA E INFORMAÇÕES -DIREI. Produto Interno Bruto dos Municípios de Minas Gerais de 2016. Belo Horizonte: FJP, 2018.

Produto Interno Bruto dos Municípios de Minas Gerais de 2017. Belo Horizonte: FJP, 2020. 
FRANTZ, W. Associativismo, cooperativismo e economia solidária. ljuí (RS): Editora Unijuí, 2012. $162 \mathrm{p}$.

OCB - ORGANIZAÇÃO DAS COOPERATIVAS BRASILEIRAS. Anuário do Cooperativismo brasileiro. Brasília (DF): Sistema OCB, 2019. 122 p. 